\title{
Reflexões sobre a docência na educação profissional e tecnológica
}

\section{Reflections on teaching in professional and technological education}

\section{Reflexiones sobre la enseñanza em educación professional y tecnologica}

\author{
Barbosa, Hedlin Braga ${ }^{1}$ (Belo Horizonte, MG, Brasil) \\ ORCID ID: https://orcid.org/0000-0002-4431-332X \\ Machado, Lucília Regina de Souza² (Belo Horizonte, MG, Brasil) \\ ORCID ID: https://orcid.org/0000-0001-9029-3019 \\ Afonso, Maria Lúcia Miranda ${ }^{3}$ (Belo Horizonte, MG, Brasil) \\ ORCID ID: https://orcid.org/0000-0002-1019-6946
}

\begin{abstract}
Resumo
A Educação Profissional e Tecnológica cresce em importância no contexto atual de grande dinamismo tecnológico e mudanças significativas no mundo do trabalho. Torna-se, assim, importante refletir sobre a docência nesse campo, sobretudo diante dos desafios da educação referenciada em qualidade social e em direitos humanos. Este artigo é produto de revisão de literatura apoiada em artigos, livros, dissertações e teses sobre esse tema. Oferece elementos históricos e teóricos de interesse para a pesquisa e ações destinadas à formação pedagógica e ao desenvolvimento profissional docente pertinentes às particularidades desse contexto. Agrega, ainda, a essa discussão referenciais utilizados ordinariamente na designação do profissional considerado professor-referência.
\end{abstract}

Palavras-chave: Educação profissional. Competência docente. Prática docente. Teoria da atividade.

\begin{abstract}
Professional and Technological Education is growing in importance in the current context of great technological dynamism and significant changes in the world of work. It is, therefore, important to reflect on teaching in this field, especially in view of the challenges of education referenced in social quality and human rights. This article is the product of a literature review supported by articles, books, dissertations and theses on this topic. It offers historical and theoretical elements of interest for research and actions aimed at pedagogical training and professional teacher development relevant to the particularities of this context. It also adds to this discussion references used ordinarily in the designation of the professional considered a reference teacher.
\end{abstract}

Keywords: Professional education. Teaching competence. Teaching practice. Activity theory.

\section{Resumen}

La educación profesional y tecnológica está creciendo en importancia en el contexto actual de gran dinamismo tecnológico y cambios significativos en el mundo del trabajo. Por lo tanto, es importante reflexionar sobre la enseñanza en este campo, especialmente en vista de los desafíos de la educación a los que se hace referencia en calidad social y derechos humanos. Este artículo es el producto de una revisión de literatura respaldada por artículos, libros, disertaciones y tesis sobre este tema. Ofrece elementos históricos y teóricos de interés para la investigación y acciones dirigidas a la formación

\footnotetext{
1 UNA Guajajaras. Programa de pós-graduação em Gestão Social e Desenvolvimento Local PPG-GSDL. Centro Universitário UNA. hedlinbarbosa@yahoo.com.br

2 Núcleo de Estudos sobre Trabalho \& Educação. Faculdade de Educação. Universidade Federal de Minas Gerais. luciliamachado2014@gmail.com

3 UNA Guajajaras. Programa de pós-graduação em Gestão Social e Desenvolvimento Local PPG-GSDL. Centro Universitário UNA. luafonso@yahoo.com 
pedagógica y al desarrollo profesional docente relevantes para las particularidades de este contexto. También se agrega a esta discusión las referencias utilizadas habitualmente en la designación del profesional considerado un maestro de referencia.

Palavras-Clave: Educación profesional. Competencia docente. Práctica docente. Teoría de la actividad.

\section{Introdução}

O processo educacional, sistemático ou não, sempre integrou diferentes contextos sociais com implicações importantes para as transformações históricas. A chamada Revolução Industrial, ocorrida na Europa nos séculos XVIII e XIX, trouxe consigo a substituição do trabalho artesanal pelo assalariado e o uso de máquinas. Ocasionou, também, a necessidade da educação profissional da classe trabalhadora seja para a recuperação pelo capital dos conhecimentos práticos aprisionados nas corporações de ofício ou para a formação das novas gerações de operários em correspondência com as demandas industriais.

As profundas modificações no modo de produzir a existência humana na atualidade têm oferecido elementos para debates sobre a emergência de uma nova lógica produtiva em nível mundial. Nesse sentido, torna-se necessário pesquisar e pensar sobre os rumos da educação profissional e tecnológica (EPT) e da docência nesse campo educacional.

Com este artigo, busca-se contribuir com tal reflexão a partir de elementos encontrados numa revisão teórica sobre o papel, atuação e formação do profissional docente considerando-se as particularidades desse contexto. Parte dessa recuperação teórica é dedicada à discussão das características consideradas importantes para que um professor seja considerado referência no processo de ensino-aprendizagem da EPT.

Leva-se em conta que essa docência exige não somente saberes técnicos, mas, também, os de cunho pedagógico, além de pressupor um olhar atento para as demandas do mundo do trabalho.

A demanda por educação profissional envolve aspectos políticos e sociais complexos e exige capacidade crítica e propositiva do profissional docente diante dos desafios encontrados, como, por exemplo, o desenvolvimento de valores e práticas para o desenvolvimento local, de territórios sociais, culturais e políticos e a articulação 
desse com o desenvolvimento - mais amplo - da sociedade.

Para apresentar os resultados da revisão realizada, o presente artigo foi dividido em seis seções a partir da introdução. A primeira trata de alguns marcos legais e ações relevantes concernentes à docência na educação profissional no Brasil. A segunda aponta para algumas das peculiaridades dos profissionais docentes da EPT, especialmente as compreensões sobre o desenvolvimento do trabalho educativo nessa modalidade de ensino. A terceira sessão aborda a formação para a docência na EPT e os desafios frente aos conhecimentos requeridos pela prática docente. $A$ quarta discorre a respeito do estudo sobre a prática pedagógica e o professorreferência na educação profissional considerando as ações pedagógicas, o saber experiencial, o saber ser e o saber-fazer. A quinta seção oferece alguns elementos da Teoria da Atividade de Leontiev, identificada como de fundamental importância para a compreensão para a reflexão sobre o trabalho docente e a organização do ensino na EPT. Na sexta e última seção, encontram-se as considerações finais.

\section{Marcos legais e ações relevantes concernentes à docência na educação profissional no Brasil}

A recuperação dessas referências reguladoras teve o objetivo de compreender particularidades da atividade docente na educação profissional e tecnológica considerando aspectos do seu percurso histórico no Brasil. O ponto de partida de destaque foi a iniciativa de Nilo Peçanha, então Presidente da República, de aprovar, em 1909, o Decreto $n^{\circ} 7.566$, inaugurador de normativas para a oferta dessa modalidade educacional com a instituição das Escolas de Aprendizes e Artífices.

Esse decreto revelou a necessidade do Estado de promover o equilíbrio social ou a harmonia entre as classes sociais mediante o disciplinamento dos chamados desfavorecidos da fortuna. Mas as 19 Escolas de Aprendizes e Artífices, então criadas, mostrou a existência de um problema para a efetivação dessa intenção, pois "[...] colocou em evidência a falta de professores especializados para esse campo educacional". (MACHADO, 2008, p.68).

Em vista dessa carência, em 1917, no Distrito Federal, Wenceslau Braz, à 
época presidente da República, criou a Escola Normal de Artes e Ofícios Wenceslau Braz, a primeira iniciativa governamental voltada à formação de docentes para a educação profissional. Essa instituição funcionou por 20 anos, mas não atendeu plenamente sua finalidade, limitando-se basicamente a formar docentes para as aulas de trabalhos manuais de escolas primárias.

Passaram-se cinco décadas até que a reforma universitária, Lei $n^{\circ}$ 5.540/68, estabelecesse a formação superior para docentes de disciplinas técnicas. Mas, já no ano seguinte, essa normativa tornou-se flexível: o Decreto-Lei n $464 / 69$ veio a admitir, em caso de falta professores e especialistas para o ensino técnico, a habilitação para essa docência mediante exame de suficiência, realizado por instituições oficiais de ensino superior, indicadas pelo Conselho Federal de Educação.

No intuito de ratificar essa liberalização de 1969, foi publicada a Portaria Ministerial $n^{\circ} 432 / 71$ instituindo dois tipos de cursos especiais, identificados como emergenciais: o Esquema I, destinado a oferecer complementação pedagógica aos diplomados em curso superior, e o Esquema II, reservado aos técnicos diplomados com vistas a oferecer, além da formação pedagógica, suplementos de conteúdos técnicos. (MACHADO, 2019).

Em 1996, com a aprovação da Lei $n^{\circ} 9.394$ de Diretrizes e Bases da Educação Nacional, a formação para o exercício da docência na educação profissional foi estabelecida formalmente, mas conforme Machado (2008) diretrizes nesse sentido têm sido estabelecidas sem consequente efetivação prática.

Assim, o que se observa é a continuidade dos programas de formação de caráter especial e emergencial. A autora adverte que "[...] uma política definida para a formação de professores que atenda a tais necessidades será certamente um grande estímulo para a superação da atual debilidade teórica e prática deste campo educacional com relação aos aspectos pedagógicos e didáticos". (MACHADO, 2008, p.15).

No Brasil, de acordo com Machado (2011), ainda se recrutam professores para a EPT, fiando-se apenas em formação específica e experiência prática, crendo que a constituição da docência se dará pelo autodidatismo. Isso contraria o disposto pela Lei n. 9.394/96, artigo 62, por meio do qual é determinado que "[...] a formação 
de docentes para atuar na educação básica far-se-á em nível superior, em curso de licenciatura, de graduação plena, em universidades e institutos superiores de educação [...]" (BRASIL, 1996).

Afirma Machado (2011) que a formação de professores para esse segmento educacional cresce em importância considerando-se o atual contexto de grande expansão da educação profissional no país e a necessidade de garantir que essa oferta educacional tenha qualidade social.

Textos legais, elaborados a partir de 2012, estabelecem orientações para a formação docente para atuação na EPT. A Resolução CNE /CEB nº 6/2012 instituiu as Diretrizes Curriculares Nacionais para Educação Profissional Técnica de Nível Médio e, em seu artigo 40, definiu que a formação inicial para a docência nessa área deve realizar-se em cursos de graduação e programas de licenciatura, ou por meio de outras formas, em conformidade com a legislação e com normas específicas definidas pelo Conselho Nacional de Educação (CNE).

Ficou estabelecido que a formação pedagógica para atuar na EPT deveria ir além da aquisição de conhecimentos técnicos especializados e que se destinaria a suprir as demandas do contexto educacional. Nesse sentido, deveria contemplar a compreensão do processo de ensino-aprendizagem, as especificidades da escola e do aluno frente ao papel do docente, os elementos próprios da esfera da EPT, as interações entre a educação e o mundo do trabalho. Para tanto, o docente deveria estar sintonizado com as mudanças sociais e tecnológicas, sendo-lhe imprescindível qualificar-se com frequência.

A possibilidade de reconhecimento de saberes adquiridos informalmente e sua certificação deu ensejo à emergência da Rede Certific4 e a expectativa de sua reorganização a partir de abril de 2014. Assim, a Portaria da Setec/MEC n 8 , de 2 de maio desse ano, ampliou o escopo dessa Rede para contemplar quatro modalidades de certificação profissional, dentre elas a de docentes da educação profissional:

a) Certificação de qualificação profissional: correspondente a curso de formação inicial e continuada ou qualificação profissional constante do Catálogo Nacional de Cursos de Qualificação Profissional, ou equivalente, mantido pelo Ministério da Educação - MEC. b) Certificação técnica:

4 A Rede Nacional de Certificação Profissional (Rede Certific) é originária de uma ação conjunta dos Ministérios da Educação e do Ministério do Trabalho e Emprego, formalizada pela Portaria Interministerial n 1.082 , de 20 de novembro de 2009, e reorganizada pela Portaria Interministerial $n^{\circ} 5$, de 25 de abril de 2014 
correspondente a curso técnico de nível médio constante do Catálogo Nacional de Cursos Técnicos, mantido pelo MEC, para possuidores de certificado de conclusão do Ensino Médio. c) Certificação tecnológica: correspondente a curso superior de tecnologia constante do Catálogo Nacional de Cursos Superiores de Tecnologia, mantido pelo MEC, para possuidores de certificado de conclusão do Ensino Médio. d) Certificação docente da educação profissional: correspondente à licenciatura em educação profissional, prevista nas diretrizes curriculares para formação de professores da educação profissional e vinculada ao exercício profissional de professores com mais de 10 (dez) anos de efetivo exercício na educação profissional e tecnológica (BRASIL, 2014a).

Entende-se que essa certificação seja capaz de compreender que o professor da EPT deve ser um profissional "[...] que sabe o que, como e porque fazer e que aprendeu a ensinar, para desenvolver idônea e adequadamente outros profissionais". (MACHADO, 2008a, p.18). Isso significa compreender seu papel e compromisso como educador, independentemente de outra atividade que venha a ter, contribuindo, assim, como participante ativo para o desenvolvimento da educação profissional.

\section{Peculiaridades dos profissionais docentes da EPT}

Neste artigo, assume-se que a educação e a prática docente podem transformar o mundo, os diferentes contextos, e isso de forma benéfica ou negativa a depender das condições e tomadas de decisões de cada indivíduo, grupo ou sociedade, atos dependentes diretamente de como o conhecimento sobre cada lugar - contextos locais e sociais - foi desenvolvido, estimulado e construído.

Nesse sentido, ao discutir o perfil profissional docente a ser formado para a educação profissional, Souza e Rodrigues ressaltam que:

A formação de professores para a Educação Profissional deve considerar as especificidades e complexidades do trabalho docente nessa área e romper com a fragmentação e a improvisação que marcaram historicamente essa modalidade de ensino e educação no Brasil (SOUZA E RODRIGUES, 2017, p. 634).

Mas, para tanto, precisa ser institucionalizada e se desenvolver num processo educacional crítico, pois a EPT depende da existência de docentes capazes de intermediar, fomentar, formar e possibilitar as inter-relações técnicas e pedagógicas na perspectiva de uma formação profissional referenciada em qualidade 
social.

Orientada ao desenvolvimento profissional docente, essa formação deve promover o conhecimento do local de inserção de cada indivíduo, da região ou território (físico, político, social, cultural, tecnológico, e assim por diante) para o qual deve se voltar e do qual valorizar as potencialidades econômicas, socioculturais e ambientais.

Esse é o cenário de inserção dos profissionais docentes da EPT, pois cabeIhes entender a destinação social e cultural dos técnicos que estão formando, questão central da construção de referências para a docência na educação profissional e tecnológica.

Tardif (2014) enfatiza que os saberes advindos da experiência dão significados à prática do docente, pois esse aprende a ensinar pela experiência vivenciada em sua atividade profissional. Assim, a docência na EPT compreende também um conhecimento experiencial da profissão.

Articulando os saberes técnicos específicos de cada área, "[...] o trabalho docente também pode ser abordado, descrito e analisado em função da experiência do trabalhador, quer dizer, do trabalho, do modo como é vivenciado e recebe significado por ele e para ele" (TARDIF, 2014, p.51). A esse respeito Machado (2019) lembra que:

A formação docente, por outro lado, não assegura por si a profissionalidade do professor [...] Refere-se, assim, a singularidades em constituição, a processos de constantes aprendizados por conta da necessidade de realizar ajustamentos em face de mudanças situacionais. São peculiaridades subjetivas que moldam a trajetória pessoal de cada professor, no caso da educação profissional, condicionadas pelas suas motivações e apreços e que contribuem para formar sua identidade profissional a partir do modo como ele se insere e se move no contexto da docência. (MACHADO, 2019, p. 211).

\section{A formação para a docência na educação profissional tecnológica}

Para além da sua experiência prática, o profissional docente da EPT enfrenta o desafio de ampliar e renovar seus conhecimentos técnicos e de buscar formação pedagógica, pois exerce uma atividade para a qual, na maioria dos casos, não foi preparado.

Pode acontecer a alguns educadores não vislumbrarem a necessidade da apropriação dos aportes pedagógicos para articular as relações entre o mundo do 
trabalho e a educação. Mas, qualquer docente da educação profissional não deixa de ser indagado, frequentemente, sobre os limites e possibilidades da sua formação inicial considerando o trabalho pedagógico a ser realizado. Isso também pode se verificar em relação à sua formação continuada, ao que a formação para a docência na EPT pode oferecer, ao como se tornar um docente desse campo educacional e ao quanto de relevância e suficiência têm seus saberes experienciais para responder aos desafios encontrados na prática pedagógica.

Tais indagações evidenciam a responsabilidade do docente da EPT de buscar o domínio e a atualização constante dos seus conhecimentos técnicos bem como a formação didática e pedagógica de caráter complementar e necessário à sua formação inicial. Lembra Machado (2008) que a sociedade atual, pautada em forte dinamismo tecnológico, demanda dos docentes a capacidade de desenvolver conteúdos e metodologias pedagógicas de forma independente e criativa e intencionada a estimular a autonomia de pensar dos alunos.

Acrescente-se, com Nóvoa (1992, p. 25), que:

A formação não se constrói por acumulação (de cursos, de conhecimentos ou de técnicas), mas sim através de um trabalho de reflexividade crítica sobre as práticas e de (re)construção permanente de uma identidade pessoal. Por isso é tão importante investir a pessoa e dar um estatuto ao saber da experiência.

Essa observação é de grande importância considerando-se o fato lembrado por Machado (2008) de que os docentes da EPT vivenciam contradições no que tange o entendimento do seu papel educacional e social, situação também referida por Fortes e Santos (2011):

[...] se por um lado necessitam dar conta dos conhecimentos técnicocientíficos constantemente renovados, por outro, devem assumir responsabilidades inerentes ao pleno desenvolvimento humano que caracteriza a função formadora de que estão investidos, o que exige a mobilização de uma racionalidade ética que se constitui na singularidade e na coletividade. (FARTES; SANTOS, 2011, p.384).

Daí a relevância do olhar atento de Nóvoa (1992) para o processo de formação docente capaz de estimular a perspectiva crítico-reflexiva e de fornecer aos docentes mecanismos de desenvolvimento do pensamento autônomo, salientando 
que estar em formação implica em investimento pessoal e a construção da identidade profissional.

Isso significa que o saber da experiência não se constrói como um "[...] circuito fechado, mas à medida de uma interação entre a experiência, a tomada de consciência, a discussão, o envolvimento em novas situações". (PERRENOUD, 1993, p.109).

As mudanças de cenários aparecem constantemente para a prática docente no contexto da educação profissional e tecnológica mostrando que ela está exposta às exigências dos setores produtivos, os quais, por sua vez, sofrem as injunções da globalização econômica e cultural. Com isso, amplia-se o recorte espacial ou o território a ser considerado pelo docente e suas correspondentes particularidades e potencialidades econômicas, sociais, culturais e ambientais.

Tais aberturas a novos contextos aparecem na leitura de Tardif (2014) quando ele remete a uma reflexão sobre a didática na atualidade, imprescindível ao profissional docente da EPT. Diz ele que:

O domínio progressivo do trabalho provoca abertura em relação à construção de suas próprias aprendizagens, de suas próprias experiências, abertura essa ligada a uma maior segurança e ao sentimento de estar dominando bem suas funções. Esse domínio está relacionado, inicialmente, com a matéria ensinada, com a didática ou com a preparação da aula. Mas são, sobretudo, as competências ligadas à própria ação pedagógica que têm mais importância para os professores. (TARDIF, 2014, p. 88-89).

Daí o valor do conhecimento prático da atividade docente, do compartilhamento das experiências profissionais adquiridas, da entrada nas especificidades do mundo do trabalho e das particularidades da educação profissional. Logo, a apropriação dos saberes relacionados às questões pedagógicas, propiciada pelo cotidiano da sala de aula, é da maior importância:

[...] o professor não é um trabalhador que se contenta em aplicar meios e que se comporta como um agente de uma organização: ele é sujeito de seu próprio trabalho e ator de sua pedagogia, pois ele é quem a modela, quem Ihe dá corpo e sentido no contato com os alunos (negociando, improvisando, adaptando). (TARDIF, 2014, p.149).

Isso se mostra mais efetivo se guiado pela finalidade de promover o êxito do estudante no seu ingresso no mundo das práticas profissionais, se o prepara de 
forma crítica para o mundo do trabalho. Nessa perspectiva, é fundamental que o docente se mostre preparado por formação pedagógica capaz de aproximá-lo das relações entre o mundo do trabalho e o da educação.

Assim, a formação pedagógica do professor da educação profissional se constitui como elemento basilar da sua prática docente, pois serão justamente seu posicionamento pedagógico, sua abertura às formas inovadoras de ensinar, sua disposição para enfrentar os desafios do processo ensino-aprendizagem as armas fundamentais a lhe garantir ser uma referência pedagógica na EPT.

\section{Estudos sobre a prática pedagógica e a identificação do professor referência}

A literatura especializada vem indicando, de maneira consistente, algumas características dos professores que se constituem referência para discentes e outros docentes. Cunha (1992) destacou cinco grupos de habilidades de ensino apresentadas pelos bons professores em seus estudos sobre o tema: a organização do contexto da aula; o incentivo à participação do aluno; o trato da matéria de ensino; a variação de estímulos; o uso da linguagem.

Ao analisar as características do professor referência, Volpato (2009) elencou quatro categorias: didática/metodologia de ensino; atitudes e qualidades pessoais do professor; domínio de conteúdo/conhecimento; interesse particular pelo aluno.

Conforme Marcel \& Cruz (2019),

Concebe-se Professor Referencial como aquele professor formador que, por sua ação pedagógica, pelo que faz em sala de aula e pelo que é como personalidade docente, adquire, para o professor em formação, um status diferenciado de seus pares, formadores de professores, em termos de qualidade - o de arquétipo de prática para o professor em formação (MARCEL; CRUZ, 2019, p.366).

Para Veiga (2008), o professor referência desenvolve saberes essenciais à sua atuação docente e sua identidade docente se faz ao longo da vida profissional, com base nos saberes profissionais e em atribuições de ordem ética e deontológica.

Na categorização de Nóvoa (1992), os saberes docentes compreendem: o saber das disciplinas, o saber da experiência e o saber especializado em educação. Uma quarta dimensão, que se refere à identidade pessoal/intersubjetiva, foi 
acrescentada por Saul (1996).

Saviani (1996, p.147) referiu-se a um conjunto de saberes que "[...] todo educador deve dominar e, por consequência, devem integrar o processo de sua formação", quais sejam: o saber atitudinal, o saber crítico-contextual, os saberes específicos, o saber pedagógico e o saber didático-curricular.

Tardif (2014), a respeito dos saberes docentes, distinguiu a sua relação com a formação profissional dos professores e com o próprio exercício da docência. Nesse sentido, destacou quatro tipos diferentes de saberes referentes à atividade docente: os saberes da formação profissional (relacionados às técnicas e métodos de ensino, saber-fazer); os saberes disciplinares (formação relativa aos diversos campos do conhecimento); os saberes curriculares (específicos da instituição educacional na qual o docente deve aprender e aplicar) e, por fim, os saberes experienciais (desenvolvidos pelos próprios professores por meio da prática docente, saber-fazer e saber ser).

O autor destaca que o saber do professor está relacionado com os diversos contextos sociais e não somente com o trabalho docente:

[...] o saber não é uma coisa que flutua no espaço: o saber dos professores é o saber deles e está relacionado com a pessoa e a identidade deles, com a sua experiência de vida e com a sua história profissional, com as suas relações com os alunos em sala de aula e com os outros atores na escola etc. (TARDIF, 2014, p.11).

Tardif (2014) ainda afirmou que:

[...] embora os professores utilizem diferentes saberes, essa utilização se dá em função de seu trabalho e das situações, condicionamentos e recursos ligados a esse trabalho [...] as relações dos professores com os saberes nunca são relações estritamente cognitivas: são relações mediadas pelo trabalho que lhes fornece princípios para enfrentar e solucionar situações cotidianas. (TARDIF, 2014, p.17).

Em vista disso, são saberes pautados no saber-ser, que têm no docente seu sujeito e protagonista, estando, assim, fortemente marcados pelas experiências de vida e profissionais. Há que se destacar a relevância desses saberes para a prática pedagógica do docente, sua aproximação com as relações mediadas pelo trabalho, 
fundamentais para o enfrentamento e solução de situações cotidianas de sua atuação.

Não obstante, Lima e Cunha (2018, p.16) entendem "[...] que é durante a atividade de trabalho, em confronto com a realidade da sala de aula, em um tempo e espaço específico, que o professor da educação profissional constrói seus saberes docentes". Isto é, são saberes da experiência, vindos de competências adquiridas na ação pela ação, saberes estes adquiridos no exercício da profissão.

Volpato $(2011$, p.101) a partir de um estudo sobre o bom professor acredita que:

Na sua prática, o "Bom Professor" necessita de entrelaçar as dimensões Humana, Técnica e Ideológica, colocando no centro do processo de aprendizagem a relação interpessoal, organizando e sistematizando a prática pedagógica enquadrada numa cultura específica que se espera seja reproduzida pelos estudantes.

Essa autora entende que a prática pedagógica sistematizada, sensível às necessidades do discente e aliada à cultura específica do meio seja fundamental para a formação do professor, de modo a dar-Ihe oportunidade de compreender e reproduzir as experiências interpessoais.

Tardif (2014) entende que o pensamento da docência se desenvolve a partir da prática profissional docente, dos saberes da experiência profissional, baseados no seu trabalho cotidiano e no conhecimento de seu meio. Nesse sentido, são saberes que surgem da experiência e são por ela validados. A cada reflexão sobre sua prática, o professor se descobre com uma nova identidade docente, delimitando seu modo de ser professor, de se ver e de entender sua profissão.

Assim, pode-se entender que a docência se faz de saberes e esses se conectam ao saber pedagógico, visto que o processo de ensino-aprendizagem constitui a parte significativa da ação docente, mediante suas percepções e interpretações em função da sua adequação ao ensino e interação com o aluno. É nessa relação que são estabelecidos e legitimados os seus saberes docentes.

\section{Teoria da Atividade de Leontiev e docência na educação profissional tecnológica}

Leontiev (1978, s.p.) nomeia atividade como o "[...] processo que é eliciado e dirigido por um motivo - aquele no qual uma ou outra necessidade é objetivada" e 
diz que "[...] por trás da relação entre atividades, há uma relação entre motivos". Nesse sentido, é importante elucidar que, na atividade docente, os motivos induzem a atividade do aluno, ou seja, eles constituem uma conexão entre o sujeito e o mundo no qual vive e decorrem da sua busca de satisfação de suas necessidades.

Quando na construção educacional se supera a limitada compreensão orgânica e biológica do processo de hominização e se move a compreender as relações entre aprendizagem e ensino como processo cultural, passa-se a compreender que, historicamente, a educação também deve ser mediada, considerando a apropriação dos artefatos culturais resultantes da práxis social.

Para tanto, Leontiev (2014) parte da concepção marxista de que o homem se caracteriza fundamentalmente por sua atividade criadora, impulsionado por uma necessidade de transformar o ambiente em que vive de forma a adaptá-lo a finalidades que busca concretizar e, dentre essas transformações, incluem-se também a ciência, a arte, a cultura, como atributos indispensáveis à satisfação de suas necessidades.

$\mathrm{Na}$ perspectiva do materialismo histórico-dialético, o processo de ensino pode assumir uma intencionalidade emancipatória já que o objeto corresponde a necessidade humana objetiva e o "[...] aluno apropria-se da estrutura da atividade humana, com suas ações". (LEONTIEV, 2014, p.189-207).

O autor fundamentou seus trabalhos em uma concepção materialista histórico-dialética do mundo, a fim de compreender a atividade humana e os processos psicológicos do movimento de produção de conhecimento. A atividade humana é a categoria central dessa concepção e também chave para a construção da aprendizagem e do desenvolvimento da personalidade. Machado \& Machado (2018) explicam que:

[...] o materialismo histórico compreende a atividade humana em sua forma inicial e principal, como prática sensível, por meio da qual o homem entra em contato com o mundo dos objetos e sobre eles exerce influência, processo que também o influencia, que o faz tomar consciência de si e da realidade circundante, que tem caráter objetivo. (MACHADO; MACHADO, 2018, p.154155).

Em vista disso, satisfazer uma necessidade é encontrar o motivo da atividade, o seu objeto. Assim, a atividade só existe se há um motivo. É, portanto, no objeto que se encontra o real motivo de uma atividade. Um professor, por exemplo, 
tem no objeto do seu trabalho, a aprendizagem dos seus alunos, aquilo que orienta sua atividade docente. Esse seria o motivo interno à sua atividade. (MACHADO; MACHADO, 2018, p.157).

Partindo desse pressuposto, Leontiev associa o desenvolvimento da consciência do aluno aos motivos ou fins da atividade de estudo, ao seu objeto. Por isso, Moura et al. (2010) defendem que, para organizar didaticamente o ensino, o professor deve refletir sobre os processos psíquicos a serem mobilizados em uma determinada atividade e verificar se o processo metodológico adotado relaciona-se com o motivo que a impulsiona.

Leontiev (1978) ressalta que, para se apropriar de um objeto, o homem precisa relacionar-se com outros homens, ou seja, se colocar em comunicação, pois não há apropriação e aprendizagem realizadas por indivíduos isolados do mundo que os cerca.

Lembra Leontiev (1978, s/p), que o "[...] pensamento e o saber de uma geração formam-se a partir da apropriação dos resultados da atividade cognitiva das gerações precedentes". Ou seja, a aprendizagem pressupõe apropriar-se da experiência social e dos artefatos necessários à relação ativa do sujeito com a realidade.

Esse processo de apropriação passa pela educação como condição indispensável, pelo trabalho docente sistematizado e organizado capaz de levar o estudante a realizar atividades e, com isso, desenvolver a formação do seu pensamento teórico. Esse trabalho pedagógico deve contar com os elementos significativos, que aproximem os alunos de sua cultura e que possam se constituir em memórias afetivas, cognitivas e/ou simbólicas.

Segundo Moura et al. (2010, p.226), ao intervir como mediador do processo de aprendizagem do aluno, o professor se constitui como individualidade, humanizase, forma-se. Esse processo é orientado pelo motivo de sua atividade. Realizar esse motivo é condição da produção do sentido pessoal da sua atividade.

A partir das contribuições oferecidas por Leontiev (1978), pode-se, portanto, compreender os desafios implicados na formação do docente da educação profissional e tecnológica. Essa não pode estar fora do movimento da história, 
desconectada da experiência cultural da humanidade, não implicada com a construção do conhecimento e o desenvolvimento da personalidade dos educandos como sujeitos ativos.

O principal desafio consiste em desenvolver a atividade docente de forma sistematizada e organizada, reproduzindo as linhas da história humana reunidas no objeto ou motivo da aprendizagem e na identidade da história do próprio educando, tendo por perspectiva a objetivação de sua personalidade e a apropriação das "[...] aquisições do desenvolvimento histórico da sociedade". (LEONTIEV, 1978, p.264).

Para tanto, é importante valorizar a formação pedagógica para o exercício do trabalho docente na educação profissional e tecnológica. Não é uma tarefa simples associar a construção do conhecimento com o processo de aprendizagem e o desenvolvimento da personalidade do indivíduo.

A forma como cada um se coloca em interação com o mundo circundante e as necessidades daí originadas produz motivos ou objetos de ensino-aprendizagem particulares. É por isso que Leontiev (1978) menciona que a tarefa da organização do ensino para uma efetiva apropriação de conhecimentos requer do docente entender sua importante função mediadora.

\section{Considerações finais}

Os resultados da revisão de literatura tratada neste artigo trazem elementos para a reflexão crítica, construtiva e contextualizada sobre questões relativas à docência na educação profissional e tecnológica.

O senso comum de que esse trabalho pedagógico deve se dar pela mera transmissão de conteúdos e técnicas a serem aprendidos pelos alunos precisa ser questionado. $\mathrm{O}$ ato de transmitir consiste em entregar algo pronto. Trata-se de uma abordagem tecnicista, que está na contramão das mudanças nas formas de se apropriar dos conhecimentos produzidos pela humanidade.

$O$ docente da EPT faz parte de um processo educativo mais amplo, caracterizado por trocas de experiências e de saberes, por espaços de formação mútua e coletiva. Pelo olhar crítico para a EPT, em suas limitações atuais, o docente pode compreender-se como um educador cuja atividade de educar não se define pela subserviência aos ditames do mercado de trabalho. 
Atento à ampliação dos seus saberes tecnológicos, cabe-lhe desenvolver também seus saberes pedagógicos utilizando-se das mais diversas estratégias e recursos disponíveis e da reflexão sobre seu dia a dia de sala de aula, saberes experienciais e iniciativas inovadoras.

Trata-se de um processo que possibilita ao professor tornar-se autônomo, diferenciado, uma referência na educação profissional, um parceiro do educando nos seus projetos de vida, uma peça fundamental na construção de uma sociedade humanizada, respeitosa dos direitos humanos e atenta ao desenvolvimento das potencialidades humanas.

\section{Referências}

BRASIL. Decreto Lei $n^{\circ} 7.566$, de 23 de setembro de 1909. Brasília, DF: Diário Oficial da União [2017]. Disponível em: http://portal.mec.gov.br/setec/arquivos/pdf3/decreto_7566_1909.pdf. Acesso em 8 set. 2019.

BRASIL. Lei n 378, de 13 de janeiro de 1937. Diário Oficial da União - Seção 1 15/1/1937, Página 1210 (Publicação Original). Disponível em: https://www2.camara.leg.br/legin/fed/lei/1930-1939/lei-378-13-janeiro-1937-398059publicacaooriginal-1-pl.html. Acesso em 30 jan. 2020.

BRASIL. Lei n 4.024 , de 20 de dezembro de 1961. Brasília, DF: Diário Oficial da União [2018]. Disponível em: http://www2.camara.leg.br/legin/fed/lei/1960-1969/lei-4024-20dezembro-1961-353722-publicacaooriginal-1-pl.html. Acesso em 8 set. 2019.

BRASIL. Lei n ${ }^{\circ}$ 5.540, de 28 de novembro de 1968. Brasília, DF: Diário Oficial da União [2018]. Disponível em: http://www.planalto.gov.br/ccivil_03/LEIS/L5540.htm. Acesso em 8 set. 2019.

BRASIL. Lei $n^{\circ}$. 9.394/96, de 20 de dezembro de 1996. Brasília, DF: Congresso Nacional [2019]. Disponível em: http://www.planalto.gov.br/ccivil_03/LEIS/L9394.htm. Acesso em 2 fev. 2019.

BRASIL. MEC. MTE Portaria Interministerial $n^{\circ} 5$, de 25 de abril de 2014. Dispõe sobre a reorganização da Rede Nacional de Certificação Profissional - Rede Certific. Diário Oficial da República Federativa do Brasil, Brasília, DF, 2 mai. 2014. v. 82, p. 14. 2014a.

BRASIL. MEC. Setec. Portaria SETEC/MEC n 8, de 2 de maio de 2014. Regulamenta o desenvolvimento de processos de certificação profissional no âmbito da Rede Nacional de Certificação Profissional - Rede Certific. Brasília, DF: 2 de maio de 2014b. 
CUNHA, M. I. O bom professor e sua prática. $2^{a}$ ed. Campinas, SP: Papirus, 1992.

LEONTIEV, A. N. Atividade e consciência. Trad. de Marcelo José de Souza e Silva. Dialectus, ano 2, n. 4, jan.-jun. 2014, p. 184-210. Disponível em: <http://www.revistadialectus.ufc.br/index.php/RevistaDialectus/article/view/122/81>.

LEONTIEV, A. N. A formação da personalidade. In: LEONTIEV, A. N. Atividade, consciência, personalidade. Cap. 5. Atividade e personalidade. Disponível em: https://www.marxists.org/portugues/leontiev/1978/activ_person/cap05.htm.

LEONTIEV, A. O desenvolvimento do psiquismo. Lisboa: Livros Horizonte, 1978.

LIMA, N. V.; CUNHA, D. M. Saberes docentes: as políticas de reconhecimento de saberes dos professores da educação profissional no Brasil. Educ. rev., Belo Horizonte, $\quad$ v. $34, \quad 2018 . \quad$ Disponível em: $<$ http://www.scielo.br/scielo.php?script=sci_arttext\&pid=S010246982018000100119\& Ing=en\&nrm=iso>. Acesso em 24 fev. 2020.

MACHADO, L. R. de S. Diferenciais inovadores na formação de professores para a educação profissional. Revista Brasileira de Educação Profissional e Tecnológica. Ministério da Educação, Secretaria da Educação Profissional e Tecnológica, v.1, n. 1, jun. 2008a.

MACHADO, L. R. de S. Formação de professores para a educação profissional e tecnológica: perspectivas históricas e desafios contemporâneos. In: MEC/INEP. (Org.). Formação de Professores para Educação Profissional e Tecnológica. $1^{a}$ ed. Brasília: MEC/INEP, 2008b, v. 8, p. 67-82.

MACHADO, L. R. de S. O desafio da formação dos professores para a EPT e Proeja. Educ. Soc., Campinas, v. 32, n. 116, p. 689-704, jul.-set. 2011.

MACHADO, L. R. de S.. Saberes tecnológicos, teoria da atividade e processos pedagógicos. Trabalho \& Educação (UFMG), n. 22, 2013, p.77-93. Disponível em: <https://periodicos.ufmg.br/index.php/trabedu/article/view/8933/6423>

MACHADO, L. R. de S.. Ensino médio e técnico com currículos integrados: propostas de ação didática para uma relação não fantasiosa. In: TVescola. Programa Salto para o futuro. Ensino médio integrado à educação profissional. Boletim 7, maio/junho de 2006, p. 51-68. Setembro de 2006. 
MACHADO, L. R. de S.. Formação docente para a educação profissional: limites e possibilidades de institucionalização. Cad. Pesq., v. 26, n. 4, out./dez., 2019. Disponível em: http://dx.doi.org/10.18764/2178-2229.v26n4p200-216.

MACHADO, T. S. C.; MACHADO, L. R. de S.. A teoria da atividade de Alexei N. Leontiev e sua abordagem sobre a correlação entre motivos e sentidos pessoais. Trabalho \& Educação (UFMG), n.27, p.151-164, 2018. Disponível em: https://periodicos.ufmg.br/index.php/trabedu/article/view/9764/6890..

MARCEL, J.; CRUZ, G. B. Êthos Docente de Professores Referenciais. Educ. Real., Porto Alegre, v. 43, n. 1, p. 363-380, mar. 2018. Disponível em $<$ http://www.scielo.br/scielo.php?script=sci_arttext\&pid=S2175$62362018000100363 \&$ Ing=pt\&nrm=iso>. Acessos em: 23 fev. 2020.

MOURA, M. O.; ARAÚJO, E. S.; MORETTI, V. D.; PANASSIAN, M. L.; RIBEIRO, F.D.; $A$ atividade orientadora de ensino: unidade entre ensino e aprendizagem. Rev. Diálogo Educ., Curitiba, v. 10, n. 29, p. 205-229, jan./abr. 2010. Disponível em: https://periodicos.pucpr.br/index.php/dialogoeducacional/article/view/3094.

NÓVOA, A. (coord). Os professores e a sua formação. Lisboa: Dom Quixote, 1992. p. 13-33.

SAVIANI, D. Os saberes implicados na formação do educador. São Paulo: Unesp, 1996.

SAUL, A. M. Uma nova lógica para a formação do educador. In: BICUDO, M. A.; SILVA JÚNIOR, C. (Orgs.). Formação do educador: Dever do Estado, tarefa da universidade. São Paulo: Editora da Universidade Estadual Paulista, 1996. p. 95-112.

TARDIF, M. Saberes docentes e formação profissional. 16 ${ }^{a}$. Ed. Petrópolis. Rio de Janeiro: Vozes, 2014

VEIGA, I. P.; D’ÁVILA, C. (Orgs.). Profissão docente: Novos sentidos, novas perspectivas. Campinas: Papirus, 2008.

VOLPATO, G. Marcas de profissionais liberais que se tornaram professoresreferência. Revista Brasileira de Estudos Pedagógicos, v. 90, n. 225, p.333-351, 2009. 


\section{Hédlin Braga Barbosa}

Belo Horizonte, MG, Brasil

Possui graduação em Pedagogia pela Universidade Salgado de Oliveira (2007) com formação para Docência na Educação Infantil, Educação Especial e Séries Iniciais do Ensino Fundamental integrada á Formação para Gestão Educacional e MBA em Gestão de Pessoas (2009). Atualmente é analista de projetos educacionais - SENAI - Departamento Regional de Minas Gerais e Mestra em Gestão Social, Educação e Desenvolvimento Local pelo Centro Universitário Una ? agosto (2020).

Email: hedlinbarbosa@yahoo.com.br

Link do Lattes: http://lattes.cnpq.br/1223345608010676

\section{Lucília Regina de Souza Machado}

Belo Horizonte, MG, Brasil

Professora titular aposentada da Faculdade de Educação da Universidade Federal de Minas Gerais (1980-2001).

Email: luciliamachado2014@gmail.com

Link do Lattes: http: http://lattes.cnpq.br/0275888830144512

\section{Maria Lúcia Miranda Afonso}

Belo Horizonte, MG, Brasil

Doutorado em Educação pela Universidade Federal de Minas Gerais (1997). Tem pós doutorado pela UFSJ (2009), com bolsa da FAPEMIG. Foi professora na UFMG de 1977 a 2003, quando se aposentou. Foi editora da revista eletrônica Pesquisas e Práticas Psicossociais, no período de agosto de 2006 a agosto de 2010. Atualmente é professora do Mestrado em Gestão Social, Educação e Desenvolvimento Local (mestrado profissional e interdisciplinar) do Centro Universitário UNA-BH.

Email: luafonso@yahoo.com

Link do Lattes: http: http://lattes.cnpq.br/0275888830144512

Recebimento: 01/06/2020

Aprovação: 16/09/2020

\section{Q.Code}

\section{Editores-Responsáveis}


Revista Labor

Programa de Pós-graduação em Educação, Universidade Federal do Ceará

Fortaleza-CE-Brasil

Prof. Dr. Enéas de Araújo Arrais Neto, Universidade Federal do Ceará - UFC, Brasil

Prof. Dr. Arno Münster, Universidade de Amiens - Paris, França 